\section{Dyslipidemia guidelines}

The measures suggested by Jacques 1 Genest and colleagues ${ }^{1,2}$ for the prevention of vascular diseases, both cardiac and neurologic, indicate the magnitude of the problem of overweight in the United States and Canada. Here in Brazil, we observe a paradoxical situation: many people are afflicted with poverty and famine, yet they also have risk factors for cardiovascular problems. It thus appears that vascular risks have no regard for a country's economic status.

The new left-wing federal government in Brazil is making strong efforts in the area of social benefits, for example through the Fome Zero (Zero Hunger) program. However, public health doctors have no particular preoccupation with vascular disease, and suboptimal nutrition may occur among Brazilians even in the presence of adequate caloric intake, as evidenced by abnormal levels of C-reactive protein, apolipoprotein, homocysteine and other compounds. ${ }^{3,4}$

Although Brazilian physicians apply evidence-based guidelines in the modern facilities that are available in our large cities, elsewhere they have adopted a system of what might be called "blind prevention," whereby patients are given acetylsalicylic acid, a statin, folic acid and vitamin E (unpublished manuscript). Physicians in the developed world tend to disapprove of this approach because it does not take into account individual patient factors such as microalbuminuria or gastric problems. This issue was recently the subject of heated debate in the "rapid responses" section of the $B M 7$ after Wald and Law ${ }^{5}$ proposed a "Polypill."

Despite the differences in medical systems and patient populations in Canada and Brazil, the guidelines presented by Genest and colleagues ${ }^{1,2}$ will be an important reminder to Brazilian health authorities that vascular disease also requires their attention.

\section{Celio Levyman}

Neurologist

Saó Paulo, Brazil

\section{References}

1. Genest J, Frohlich J, Fodor G, McPherson R (the Working Group on Hypercholesterolemia and Other Dyslipidemias). Recommendations for the management of dyslipidemia and the prevention of cardiovascular disease: summary of the 2003 update. CMA7 2003;169(9):921-4.

2. Genest J, Frohlich J, Fodor G, McPherson R (the Working Group on Hypercholesterolemia and Other Dyslipidemias). Recommendations for the management of dyslipidemia and the prevention of cardiovascular disease: 2003 update. CMAJ 2003;169(9):Online-1 to Online-10. Available: www.cmaj.ca/cgi/data/169/9/921/DC1/1 (accessed 2004 Jun 1)

3. Toole MJ, Waldman RJ. Refugees and displaced persons. War, hunger, and public health. $7 A M A$ 1993;270(3):600-5.

4. Rice AL, Sacco L, Hyder A, Black RF. Malnutrition as an underlying cause of childhood deaths associated with infectious diseases in developing countries. Bull World Health Organ 2000;78(10):1207-21.

5. Wald NJ, Law MR. A strategy to reduce cardiovascular disease by more than $80 \%$. BMF 2003;326:1419-24.

Competing interests: None declared.

DOI:10.1503/cmaj.1031819

A lthough I appreciate the updated guidelines on the management of dyslipidemia developed by Jacques Genest and colleagues, ${ }^{1,2}$ I fear that family physicians will find it difficult to follow the recommendations because the requirements of individual patients are not well addressed.

In the guidelines, information about risk is not presented in a patient-friendly fashion. Patients (and their physicians) are often uncertain about the meaning of risks expressed as a percentage, and decisions about the correct course of action often depend on the way in which statistics are framed. ${ }^{3}$ For example, according to the model for estimating risk (presented in the appendix of the print summary ${ }^{1}$ and as Table 1 in the full guidelines ${ }^{2}$ ), a 75-year-old male nonsmoker with a systolic blood pressure of $145 \mathrm{~mm}$ $\mathrm{Hg}$, a total cholesterol level of 5.4 $\mathrm{mmol} / \mathrm{L}$ and a high-density lipoprotein cholesterol level of $1.1 \mathrm{mmol} / \mathrm{L}$ has a total of 15 risk points, representing a 10year risk of a coronary event of $20 \%$. On the basis of results from the Heart Protection Study, as summarized by Genest and colleagues, ${ }^{2}$ treatment with simvastatin should reduce that risk by $24 \%$, to approximately $15 \%$. A reduction in risk of nearly $25 \%$ sounds impressive, but an alternative way of presenting the same information would be to say that for every 100 patients taking simvastatin for 10 years, 95 would receive no benefit ( 80 would not have experienced an event even if untreated, and 15 would experience an event even though they were taking the medication).

Even more confusingly, the risk calculator $^{1,2}$ will not show our hypothetical patient any evidence of benefit with simvastatin therapy: despite a probable reduction in cholesterol, this treatment will not change his total risk points, which will remain stubbornly at 15 .

Dyslipidemia does not exist in isolation and is generally confounded by other cardiac hazards. I believe that the risk should have been presented in a pictorial fashion, expressing the relative importance of smoking cessation and reduction in blood pressure and cholesterol. The tables in the New Zealand ${ }^{4}$ and British guidelines seem much more usable tools than the arithmetic calculation suggested by Genest and colleagues. ${ }^{1,2}$

\section{Hugh R. Hindle}

Family Physician

Hinton, Alta.

\section{References}

1. Genest J, Frohlich J, Fodor G, McPherson R (the Working Group on Hypercholesterolemia and Other Dyslipidemias). Recommendations for the management of dyslipidemia and the prevention of cardiovascular disease: summary of the 2003 update. CMA7 2003;169(9):921-4.

2. Genest J, Frohlich J, Fodor G, McPherson R (the Working Group on Hypercholesterolemia and Other Dyslipidemias). Recommendations for the management of dyslipidemia and the prevention of cardiovascular disease: 2003 update. CMA7 2003; 169(9):Online-1 to Online-10. Available: www.cmaj .ca/cgi/data/169/9/921/DC1/1 (accessed 2004 Jun 1).

3. Gigerenzer G, Edwards A. Simple tools for understanding risks: from innumeracy to insight. BM7 2003;327:741-4.

4. Dyslipidaemia Advisory Group, on behalf of the Scientific Committee of the National Heart Foundation of New Zealand. 1996 National Heart Foundation guidelines for the assessment and management of dyslipidaemia. NZ Med F 1996;109:224-31.

5. Working Party of the British Cardiac Society and British Hyperlipidaemia Association and British Hypertension Society. Joint British recommendations on prevention of coronary heart disease in clinical practice. Heart 1998;80(Suppl 2):S1-29.

Competing interests: None declared.

DOI:10.1503/cmaj.1031820

\section{[One of the authors responds:]}

Celio Levyman mentions the mas$\checkmark$ sive demographic changes taking place in countries with emerging market economies, where urbanization is occurring at an unprecedented rate. In Costa 
Rica, urbanization caused a marked shift in dietary and exercise patterns with a concomitant increase in cardiovascular risk factors, ${ }^{1}$ and at a global level such changes have been emphasized by Yusuf and colleagues. ${ }^{2}$ We agree that the recommendations of Wald and $\mathrm{Law}^{3}$ may not be appropriate in a primary prevention setting. The risk reduction estimates calculated by Wald and Law may be overly optimistic and could distract attention from an unambiguous message promoting exercise, diet, weight reduction and smoking cessation.

Hugh Hindle points out the dilemma caused by elevation of cholesterol in asymptomatic elderly patients. As he notes, most of their risk is attributable to age, and cholesterol reduction might not be expected to yield a marked decrease in cardiovascular disease in a primary prevention setting. This finding is echoed by the relatively small benefit observed in the PROSPER (PROspective Study of Pravastatin in the Elderly at Risk) study, in which pravastatin $(40 \mathrm{mg} /$ day $)$ was given to elderly subjects. ${ }^{4}$ However, many guidelines are available for the treatment of high cholesterol, and the 1998 guidelines cited by Hindle are now somewhat out of date. The Canadian guidelines, ${ }^{5}$ which are offered in a single-page format for ease of use, are based on data from recent studies and are among the most aggressive of currently available guidelines.

\section{Jacques Genest}

Working Group on Dyslipidemia and

Coronary Artery Disease Prevention Montréal, Que.

\section{References}

1. Campos H, Mata L, Siles X, Vives M, Ordovas JM, Schaefer EJ. Prevalence of cardiovascular risk factors in rural and urban Costa Rica. Circu lation 1992;85(2):648-58.

2. Yusuf S, Reddy S, Ounpuu S, Anand S. Global burden of cardiovascular diseases: part I. General considerations, the epidemiologic transition, risk factors, and impact of urbanization. Circula tion 2001;104(22):2746-53.
3. Wald NJ, Law MR. A strategy to reduce cardiovascular disease by more than $80 \%$. BMF 2003;326(7404):1419-24

4. Shepherd J, Blauw GJ, Murphy MB, Bollen EL, Buckley BM, Cobbe SM, et al; PROSPER Study Group. Pravastatin in elderly individuals at risk of vascular disease (PROSPER): a randomised controlled trial. Lancet 2002;360(9346):1623-30.

5. Genest J, Frohlich J, Fodor G, McPherson R (the Working Group on Hypercholesterolemia and Other Dyslipidemias). Recommendations for the management of dyslipidemia and the prevention of cardiovascular disease: summary of the 2003 update. CMA7 2003;169(9):921-4.

Competing interests: The author has received speaker fees from various drug companies, including those that manufacture drugs used to treat dyslipidemia and cardiovascular disease; he has also been a member of advisory boards of various drug companies.

DOI:10.1503/cmaj.1040734

\section{Letters from Egypt}

$M$ y coeditor, Philip Teigen, and I thank Mark Clarfield for his review $^{1}$ of our volume Dearest G... Yours WO: William Osler's Letters from Egypt to Grace Revere Osler.

Clarfield comments on the derivation of the term "khamsin." We had 2 Egyptologists check the manuscript, one of whom pointed out that there were several views regarding this word and its meaning, which depended on local interpretation. He stated that the one to which we referred was probably as valid as any.

\section{Lawrence D. Longo}

Director, Center for Perinatal Biology

Loma Linda University School of

Medicine

Loma Linda, Calif.

\section{Reference}

1. Clarfield AM. Osler on the Nile [book review]. CMA7 2004;170(5):833.

DOI:10.1503/cmaj.1040654

\section{[The author responds:]}

$\mathrm{V}$ arious sources, including the BBC's weather Web site, ${ }^{1}$ the Encyclopedia Britannica ${ }^{2}$ and 2 dictionaries (one in English ${ }^{3}$ and the other a standard Arab-English work ${ }^{4}$ ) all attribute the origin of the word "khamsin" to the Arabic term for "fifty." This approximates the number of days these blasted winds torture those of us who live in the Middle East.

Beyond these citations, however, there is an even stronger refutation of the explanation offered by the Egyptologists that Longo and his coauthor consulted, that the word is derived from the Arabic for "five" (supposedly referring to the fifth month, May, "when the storms are at their worst"). Unlike the Jewish and secular calendars, the Muslim calendar is based on the lunar cycle and thus has no standard fifth month (or any numeric month, for that matter) occurring in the same season of each year. As such, Islam's holy days take place in different seasons each year, and the fifth month rotates around the Gregorian calendar.

I would like to repeat (as I mentioned in my original review ${ }^{5}$ ) that this small error can hardly be said to detract significantly from this excellent book, which I once again highly recommend to readers of $C M A 7$.

\section{A. Mark Clarfield}

Ben Gurion University of the Negev

Beersheva, Israel

\section{References}

1. Giles B. The khamsin. In: Weather $A-Z$ [online]. London (UK): BBC. Available: www.bbc .co.uk/weather/features/az/alphabet32.shtml (accessed 2004 Apr 25).

2. Khamsin. In: Encyclopaedia Britannica [online]. Chicago: Encyclopaedia Britannica Inc. Available: www $\cdot$ britannica.com/eb/article? eu $=46320$ (accessed 2004 Apr 25).

3. Funk \& Wagnall's Canadian college dictionary. Markham (ON): Fitzhenry and Whiteside; 1989. p. 742 .

4. Wehr H. Dictionary of modern written Arabic. Ithaca (NY): Cornell University Press; 1961. p. 262.

5. Clarfield AM. Osler on the Nile [book review]. CMA7 2004;170(5):833.

DOI:10.1503/cmaj.1040778 